\title{
Solution-based emerging hybrid solar cells
}

\author{
Tsukasa Yoshida $^{1} \cdot$ Matthew S. White $^{2} \cdot$ Gregor Trimmel $^{3}\left(\right.$ Philipp Stadler $^{4}$
}

Received: 22 March 2017/Accepted: 28 March 2017/Published online: 1 April 2017

(C) Springer-Verlag Wien 2017

The first special part of this issue of Monatshefte für Chemie-Chemical Monthly comprises contributions of Symposium S "Solution-based emerging hybrid solar cells" organised within the fall meeting of the European Materials Research Society, which took place in Warsaw, Poland, from September 19 to 22, 2016.

The symposium brought together scientists from different areas of emerging solution processable solar cells, i.e. hybrid organic-inorganic perovskite, quantum-dot, organic and dye-sensitized solar cells and enabled a fruitful exchange of know-how between the different emerging solar cell communities. Physicists, chemists, electrical engineers, and materials scientists from more than ten countries were participating creating a strong interdisciplinary and international atmosphere. The symposium aimed at a knowledge transfer within emerging material classes to design a high-performance scenario for all of them. In the light of the impressive development in perovskite solar cells competing with state-of-the-art

Gregor Trimmel

gregor.trimmel@tugraz.at

1 Department of Chemistry and Chemical Engineering, Faculty of Engineering, Research Center for Organic Electronics, Yamagata University, Jonan 4-3-16, Yonezawa, Yamagata 992-8510, Japan

2 Department of Physics, University of Vermont, Cook Building 82 University Pl, Burlington, VT 05405-0125, USA

3 Institute for Chemistry and Technology of Materials (ICTM), NAWI Graz, Graz University of Technology, Stremayrgasse 9, $8010 \mathrm{Graz}$, Austria

4 Linz Institute for Organic Solar Cells (LIOS), Institute for Physical Chemistry, University of Linz, Altenbergerstr 69, 4040 Linz, Austria established silicon technologies at power conversion efficiencies above $20 \%$, a focus of this symposium was devoted to this class of materials. New device fabrication methods, spectroscopic and electrical studies as well as stability issues of organo-lead halide perovskites and alternative, lead-free perovskites have been presented. Additional sessions were focusing on organic solar cells comprising new insights in polymer synthesis, device physics and architectures, high voltage and tandem solar cells, as well as charge transfer solar cells. Furthermore, new research ideas from the field of quantum-dot solar cells and nanocrystal/polymer hybrid solar cells, as well as advanced characterization techniques were highlighted. The symposium was rounded up by two poster sessions in the evening giving all scientists an enriching platform for scientific exchange.

In this special part of the current issue selected research articles and a review are presented covering most aspects of the symposium. Höfler et al. present in an extensive review on the progress in lead-free perovskites for photovoltaics, as one of the current discussions is focusing on the possibility to replace toxic lead compounds by less harmful materials [1]. The importance of fine tuning of the photovoltaic properties of organo-lead halide perovskites by mixing different halides, e.g. iodide and bromide, is discussed in contributions from the group of Schlettwein [2] and from the group of Mari [3]. The paper of Tsuda et al. presents an interesting approach on the electrochemical selfassembly of copper rhodanide and 4-(N,N-dimethylamino)-4'-( $N^{\prime}$-methyl)stilbazolium tosylate yielding interesting hybrid structures. By dissolving the organic component a highly porous crystalline CuSCN material can be obtained [4]. Knall and coworkers report on the synthesis of a conjugated, low 
bandgap alternating copolymer with pyrrolopyridazinedione as electron poor and benzodithiophene as electron rich monomers and investigated the device properties of this polymer in combination with fullerene-derivatives in organic solar cells, as well as using $\mathrm{CuInS}_{2}$-nanocrystals in hybrid solar cells [5]. Dunst et al. report on the photovoltaic properties of quinacridone and quinacridone derivatives in homojunction solar cells [6]. Moreover, the group of Stadler showed an interesting alternative doping approach for PEDOT to yield highly conductive polymer thin films [7].

At the end, we would like to thank all participants of the conference and especially all authors of this special part for their contributions, and additionally Peter Gärtner and Christian Hametner for their support making this special part possible.

\section{References}

1. Hoefler SF, Trimmel G, Rath T (2017) Monatsh Chem. doi:10. 1007/s00706-017-1933-9

2. Ruess R, Stumpp M, Schlettwein D (2017) Monatsh Chem. doi:10. 1007/s00706-016-1891-7

3. Slimi B, Mollar M, Ben Assaker I, Kriaa A, Chtourou R, Marí B (2017) Monatsh Chem. doi:10.1007/s00706-017-1958-0

4. Tsuda Y, Sun H, Sun L, Okada S, Masuhara A, Stadler P, Sariciftci NS, White MS, Yoshida T (2017) Monatsh Chem. doi:10.1007/ s00706-017-1929-5

5. Knall AC, Jones AOF, Kunert B, Resel R, Reishofer D, Zach PW, Kirkus M, McCulloch I, Rath T (2017) Monatsh Chem. doi:10. 1007/s00706-017-1949-1

6. Dunst S, Karner E, Coppola ME, Trimmel G, Irimia-Vladu M (2017) Monatsh Chem. doi:10.1007/s00706-017-1971-3

7. Farka D, Coskun H, Bauer P, Roth D, Bruckner B, Klapetek P, Sariciftci NS, Stadler P (2017) Monatsh Chem. doi:10.1007/ s00706-017-1973-1 